\title{
Effects of Meditation Technique on Test Anxiety Among Secondary School Students in Anambra State, Nigeria
}

\author{
Chinyelu Nwokolo, PhD \\ Department of Guidance and Counselling, \\ Nnamdi Azikiwe University, Awka, Anambra State, Nigeria \\ Obianuju Blessing Mokwelu, MED \\ Anambra State Nigeria \\ Uche, Eva Eneasator, PhD \\ Nwafor Orizu College of Education, Nsugbe, Anambra State Nigeria
}

Doi: 10.19044/esj.2017.v13n32p271 URL:http://dx.doi.org/10.19044/esj.2017.v13n32p271

\begin{abstract}
Test anxiety constitutes a serious academic impediment to lots of students in schools. This study investigated the Effects of Meditation technique on test anxiety among secondary school students in Anambra State, Nigeria. Two research questions guided the study and two null hypotheses were tested at 0.05 level of significance. Quasi-experimental research was adopted in carrying out the study. A sample size of 101 adolescents was chosen from a population of 475 adolescents in SS2 with test anxiety. The sample was derived from two schools selected using purposive sampling technique based on the number of students that scored high on Test Anxiety Inventory. Data relating to research questions were analysed using statistical Mean while data relating to hypothesis was analysed using Analysis of Covariance (ANCOVA). Findings from the study revealed among others that though the reduction of secondary school students' test anxiety after meditation technique differed significantly with that of the conventional counselling group, meditation technique was not effective on secondary school students' test anxiety. It further revealed that meditation technique reduced the secondary school students' test anxiety. Based on the findings, implications of the study were noted and recommendations made that since the technique meditation was found not to be effective, but significantly reduced the test anxiety of the participants, the technique should not be used alone by the guidance counsellors in helping clients, especially students in overcoming their test anxiety in schools.
\end{abstract}


Keywords: Meditation technique, group counselling, test, anxiety, secondary school, students

\section{INTRODUCTION \\ Background to the Study}

In Nigeria, including Anambra State, some students fail because they are tensed up during tests as a result of anxiety. This has been evidenced when students become fearful, unusually panicky, trembling and sometimes faking illness when faced with tests (Egbochukwu, Obodo \& Obadan, 2009). This becomes a major concern because the tested individuals will expect to be regarded as competent and able to meet the standards of the set criteria.

Anxiety is a global menace. It is regarded as a general term for several disorders that cause nervousness, fear, apprehension and worry (Bouras \& Holt, 2007). Anxiety triggers the physiological stress response, which can impede memory recall. It is a human reaction to any unknown situation and a pervasive problem with far-reaching educational outcomes for many students Spelberger (2005) described anxiety as a perceived notion of psychological distress which occurs due to the expectation of a confusing and potentially threatening event. It is a feeling that students might have especially in a school situation where performance really counts.

A good number of students experience anxiety during test which in most cases lead to poor performance in school.Too much anxiety over a test situation is commonly referred to as test anxiety. Test anxiety, according to Segool, Carlson, Goforth, Von der Embse and Barterian (2013) is the emotional, physiological and behavioural responses surrounding the potential consequences of negative evaluation on an upcoming test or examination.It is a physiological condition in which people experience extreme stress, anxiety, and discomfort during and/or before taking a test. This type of anxiety creates significant barriers to learning and performance. According to Hopko, Crittendon, Grant and Wilson (2005), a student with high anxiety can fall behind academically because he or she is distracted and has impaired working memory skills when anxious. When one experiences too much anxiety, it can result in emotional or physical distress, difficulty in concentrating, and emotional worry (Vaez \& Laflamme, 2008). Also, lower performance may arise not because of intellectual problems or poor academic preparation, but because the testing situations create a sense of threat for those experiencing test anxiety.Anxiety resulting from the sense of threat then disrupts attention and memory function (Salend, 2012; Vaez \& Laflamme, 2008). Many of these students experiencing anxiety, mostly in their adolescence, often have to put forth extra effort in other to perform well because they are trying to manage their anxiety while performing a task. Test anxiety in the context of this study 
is therefore defined as a psychological condition in which people (adolescents in school) experience intense fear, worry and concern during a test.

Test anxiety is more prevalent in school setting than people could imagine and majority of text anxiety cases are not recognized easily in schools. This is because many students rarely seek help for any perceived emotional apprehensions from significant adults. Furthermore, according to Cassidy and Johnson (2002), testing situations create a sense of threat for those adolescents that are experiencing test anxiety and possibly disrupt attention and memory function. The students are usually distracted and hence find it difficult to articulate and comprehend in some situations, simple test instructions.According to Test Anxieties Disorder Association of America (2012), majority of students, mostly adolescents report being more stressed by tests and schoolwork than by anything else in their lives. Statistically, in their study, 16 - 20percentof students were reported to have high test anxiety, 18 percent reported moderately high test anxiety while high anxiety students perform 12 percentile points (about half a letter grade) below low anxiety peers.

Cassady and Johnson (2010) noted that between 25 to 40 percent of students experience test anxiety. They further stated that students who experience test anxiety tend to be easily distracted during test, experience difficulty in comprehending fairly simple directives and have trouble organising or recalling information. Such students usually end up failing a test when they have the required mental capacity to pass such test. These could be as a result of some factors such as parental pressure associated with greater worry, test irrelevant thoughts, and stronger bodily symptoms relating to anxiety during a test (Putwain, Woods, \& Symes, 2010). Other factors contributing to test anxiety of students according to Anxiety Disorder Association of America(2012) include fear of failure, procrastination, and previous poor test performance. Other characteristics of the test environment such as: nature of the task, difficulty, atmosphere, time constraints, examiner characteristics, mode of administration and physical setting could affect the level of anxiousness felt by the student (Putwain, Woods, \&Salend, 2012; Salend, 2012; Symes, 2010). Putwain and Best (2011) examined test performance among elementary children when the teacher put pressure on the children in an attempt to create a more high stress environment. Their findings indicated that children performed poorer in high threat situations and experienced more test anxiety and worrisome thoughts than when they are in a low threat environment.

Also, Kendra (2012) noted the possibility of test anxiety forming a vicious cycle; that is, the possibility that after experiencing test anxiety on test, the student may experience more anxiety on another test than he or she 
experienced on the previous test. Such student may feel helpless if the cycle continues without him or her seeking for professional help.

Tests are very important in schools; hence adolescents must take several of it in the course of their schooling for a number of reasons. For instance, the results are used to make important decisions about students and educational programmes including determining levels of subject mastery, report card grades, grade level promotions, honours, and graduation (Carter, Wehby, Hughes, Johnson, Plank, \& Barton-Arwood (2005). Also, many examinations in Nigeria are centralised and highly competitive; hence it tends to heighten the fear and tension because no student would actually like to fail.

Test anxiety has much implication for many students at all levels of which failure in examination is one of them. According to Zondi (2013), test anxiety can result in physiological, behavioural, and/or psychological effects. Physiological effects include rapid heartbeat, headache, tension, profuse perspiration; Behavioural, which includes indecisiveness, being unable to organize thoughts; while psychological, involves feelings of nervousness, restlessness and continual doubt.

This prevalent problem of test anxiousness reduces working memory, confuses reasoning, increases mistakes, and lowers test scores (Zondi, 2013). In schools, notably in Anambra State, the incidence of test anxiety is common. Researchers such as Onyekuru and Ibegbunam(2014) in their study reported further that between 25 to 40 percent of students in colleges experiences test anxiety. According to them, twenty percent of test-anxious students leave school before graduating because of repeated academic failures. Also Chapell, Blanding, Siverstein, Takashi, Newman, Gubi and Mccain (2005) similarly found a significant inverse relationship between test anxiety and grade point average among the students.

Test anxiety if untreated, can persist for years (Mychailyszyn, Mendez, $\&$ Kendall, 2010), but proper interventions can decrease anxiety and improve learning (Ozsivadjian, Knott, \&Magiati, 2012). This has been a phenomenon burning in the minds of researchers (such as Onyekuru and Ibegunam (2014), and Zondi (2013) seeking ways to unravel the cryptic threat posed by test anxiety.

Test anxiety has been conceptualised in many ways leading to many methods of approaching its treatment. The research on test anxiety appears to have existed many decades but still continues today. It emerges as a multifaceted concept which engulf different views centred on its aetiology and possible interventions..Egbochukwu, Obodo and Obadan (2009) study on the efficacy of Rational Emotive Therapy on the reduction of test anxiety among secondary school students proved effective. The meta- analysis conducted by Ergene (2003) on effective interventions on test anxiety reduction programme 
found behavioural and cognitive interventions to be effective in reducing test anxiety.

In spite of all these laudable efforts put in to curb the frightening effect of test anxiety among students, test anxiety still remains a challenge and poses a serious threat to many student populations. This explains the need to explore other psychological techniques such as meditation in handling students test anxiety.

Meditation is a useful self-calming technique that relies on the power of the mind to focus attention. Meditation relaxes the body and reduces the impact of stress(Ford, 2008). Through attention training, meditation brings about a shift toward self-observation using the techniques of relaxing the body and creating awareness, clearing the mind of negative thoughts, forming a mental guide, staying focused and managing thoughts. Thus, meditation may be useful for facilitating behavioural changes .Deikman(2003) observes that the increase in scope and clarity of the observing self which meditation encourages leads directly to freedom from habitual patterns of perception and response. The observing self redirects the intensity of the distress, obsessive thinking,automatic response patterns, and thus provides the opportunity for modification, mastery, and control of behaviour.

Early study by Shapiro and Zifferblatt (1976) compared Zen meditation with Western behavioural self-control strategies. Zen meditation is a type of meditation practiced by major school of Buddhism originating in 12th-century China that emphasizes enlightenment through meditation and insight. So, Shapiro and Zifferblattin in their study observed that in addition to relaxation and refocusing of attention, meditation involves self-observation and desensitization to thoughts, fears, and worries. Attending to the breath in a state of relaxed attention becomes a competing response that desensitizes thoughts and images, and permits increased receptivity to other thoughts, affects, or fantasies. Meditation is associated with states of physiological relaxation that can be utilized to lighten stress, anxiety, and other physical symptoms. Secondly, meditation brings about cognitive shifts that can be applied to behavioural self-observation and management, and to understanding limiting or self-destructive cognitive patterns.

The problem of test anxiety is still a major source of worry and unease to many students, parents, counsellors, teachers, and other well-meaning persons in the society. These stakeholders desire a solution to the test anxiety and it is time a definite answer is proffered. This has necessitated the need to explore other techniques in reducing test anxiety among students. There is an obvious possibility that effects of the aforementioned techniques used in previous researches may have been superficial, hence there is need for a technique with much deeper and longer-lasting effect. This study therefore is set out to investigate the effects; that is the possible change that will take place 
as a result of meditation and progressive muscle relaxation treatments administered on secondary school adolescents with test anxiety in Onitsha North local government area.

\section{Purpose of the Study}

The main purpose of this study is to investigate the Effects of Meditation technique on test anxiety among secondary school students. Specifically, the study intends to investigate;

1. The effects of progressive muscle relaxation technique on test anxiety among secondary school students.

2. Whether there is any difference in the effects of Mediation treatment techniques on test anxiety among male and female secondary school students.

\section{Scope of the Study}

This research was delimited to secondary school adolescents with high level of text anxiety in public secondary schools in Anambra State. Specifically, the study focuses on the effects of meditation technique on test anxiety among Senior Secondary School Students (S.S 2) in coeducational schools because they are not in any focused examination class. The independent variable is Meditation technique while the dependent variable is test anxiety. The moderator variable is gender.

\section{Research Questions}

The following research questions were posed to guide the study.

1. What is the difference in the pre-test and post-test test anxiety mean scores of secondary school adolescents treated with meditation technique when compared with those in the control group?

2. What is the difference in the pre-test and post-test test anxiety mean scores of male and female secondary school students treated with meditation Technique?

\section{Hypotheses}

The following null hypotheses guided the study, and were tested at the 0.05 level of significance:

1. There is no significant difference in the pre-test and post-test test anxiety Mean scores of secondary school adolescents treated with meditation technique when compared with those in the control group

2. There is no significant difference in the pre-test and post-test test anxiety Mean scores of male and female secondary school adolescents treated with meditation Technique 


\section{Method}

\section{Research Design}

This study is a quasi-experimental research. Harrington and Harrington (2006) and Nwogu (2006) described a quasi-experimental study as a type of experimental study that determines the effect of a treatment paradigm on a non-randomised sample. According to Asgari and Nunes (2011), quasiexperimental research is conducted in a natural setting rather than laboratory conditions, but in this design, variables are isolated, controlled and manipulated. In this study, the researcher adopted quasi experimental research design because the treatment was carried out in a school setting where it was not to possible conduct a true experiment.Treatments were introduced only to the experimental participants, after which the two groups (treatment and control group) are measured. The researcher will then compare the two group pre-test scores and the post test scores.

\section{Area of the Study}

The study was conducted in Anambra State, Nigeria. The researcher observed that many students in this area are usually scared of writing tests; as a result many tend to get involved in many unwholesome acts such as cheating, bribery, and sometimes bullying their fellow students, forcing them to disclose test answers to them in the examination hall just to pass. Many "miracle" centres as observed by this researcher were set up by private firms to assist candidates in cheating during examinations especially in many remote areas in the state. This sad situation could be attributed to test anxiety; as such negative phenomenon has the tendency of weakening students' will to reproduce what they have learned. The researchers therefore considered this area as a well suited area for the research study of this kind.

\section{Population of the Study}

The population of this study is 475 students in senior secondary schools (SS 2 students) from all the coeducational secondary schools in the state facing high level of test anxiety. SS 2 students were chosen because they are not in external examination class.

For the researchers to get the population of students with test anxiety in the region, they visited seven coeducational secondary schools and administered the Test Anxiety Inventory (TAI). Thus, this was regarded as the pre-test. A total of 3,016 copies of the TAI were administered to all the coeducational SS2 students with the help of four trained research assistants. Those found high in test anxiety (that is students with high scores above the norm of $34.37 / 34.77$ and above for male and female respectively as indicated in the Test Anxiety Inventory) made up the population of the study. (Source: Post Primary School Service Commission, 2015). 


\section{Sample and Sampling Technique}

The sample size for the study is 101 adolescents. This comprises of all the SS 1 adolescents chosen from the three coeducational secondary schools selected for the study. The sample size was derived from the population of 475 adolescents with high test anxiety scores from three coeducational secondary schools in Onitsha North local government area.Three schools were selected using purposive sampling technique based on the number of students that scored high on test anxiety in each of the 7 coeducational schools. The two schools with the highest number of students with high test anxiety (using the pre-test scores) served as the experimental groups I and II respectively. The sample size for each groups of Meditation, and Control respectively are 50 and 51 .

\section{Instrument for Data Collection}

The instrument that was used for assessment is Test Anxiety Inventory (TAI). The instrument was originally developed by Spielberger (1980) but revalidated in Nigeria by Omoluabi (1993). TAI has been adapted to Nigerian setting and have been used extensively in Nigeria. The Test Anxiety Inventory (TAI) is a self-report psychometric scale which was developed to measure individual differences in test anxiety as a situation-specific trait. The test contains twenty items (see Appendix). Based on 4-point rating Scale, ranging from 1 (almost never), 2 (sometimes), 3 (often), to 4 (almost always) (Spielberger, 1980). The respondents were required to indicate how frequently they experience specific symptoms of anxiety before, during and after examinations. In addition to measuring individual differences in anxiety proneness in test situations, the TAI subscales assess worry and emotionality as major components of test anxiety. All responses of the twenty items on the TAI combined to yield a total score. The TAI total score ranged from $20-80$, with higher score indicating a higher level of anxiety.

\section{Validation of the Instrument}

The instrument, Test Anxiety Inventory (TAI) was originally developed by Spielberger in 1980 but revalidated in Nigeria by Omoluabi (1993) and PerafomPsychometric Centre in 1997. The researcher therefore adopted the TAI and did not have to do any validation.

\section{Reliability of the Instrument}

Coefficient alpha of 0.92 and higher has been reported for TAI total scores (Spielberger, 1980). Additionally, TAI has good internal consistency reliability among samples of secondary school and university students. Coefficient alphas of 0.88 and 0.90 respectively have been reported for both male and female samples. Test score stability over 2-4 weeks test-retest 
interval ranged from 0.80 to 0.81 for TAI (Spielbberger, 1980). The coefficients of reliability obtained from the Nigerian samples ranges from 0.73 to 0.79 (Omoluabi, 1993).

\section{Method of Data Collection}

All the students from all the coeducational secondary schools were given the Test Anxiety Inventory to fill. The researcher and six trained research assistants went round the secondary schools to distribute 3,016 copies of the questionnaire. Each participant in their individual classes were given the instrument TAI to respond to the items. The researcher gave an introductory instruction on how to complete the questionnaire to the students. The nature of the student's responses and the purpose for which it will serve were clearly explained to the students. The researcher, with the research assistants properly assisted and guided the students on how to appropriately respond to the questionnaire, and they did. The questionnaire sheets were collected from the students immediately they finished responding to the questionnaire items and were handed to the researcher for collation and scoring.

Each response was scored according to the specification on the TAI manual. Scores that are above the Nigeria norm (34.37 for males and 34.77 for females) indicated the presence of test anxiety, while scores below this was an indication of having no problem with test anxiety. This will enable the researchers to identify test anxious students. These scores from the first administration of the questionnaire made up the pre-test. A special request was then made to the school principal for provision of adequate and conducive classroom for the administration of the treatment. After the six weeks experimental treatment and conventional group counselling, the instrument, TAI was re-administered on the students. The responses were collated, scored and analysed to determine statistical difference between the experimental and control groups.

\section{Method of Data Analysis}

The completed instruments were scored following the scoring instructions provided in the Test Anxiety Inventory (TAI) manual. Scores that are above the Nigeria norm (34.37 for males and 34.77 for females) indicate presence of test anxiety and scores below this show no problem with test anxiety. The scoring of the instrument were done in accordance with the Test Anxiety Inventory Manual, for the scoring, Almost Always $=4$, Often $=3$, Sometimes $=2$, and Almost Never $=1$.

The data relating to the research questions were analysed using the mean. The data relating to the null hypotheses were analysed using the Analysis of Co-variance (ANCOVA). 


\section{Results}

\section{Research Question 1}

What are the differences in the Pretest and Posttest test anxiety mean scores of students treated with meditation and those in the control group?

Table 1: Pretest and Posttest test anxiety mean scores of students treated with meditation and those in the control group

\begin{tabular}{lrllll}
\hline \multicolumn{1}{c}{ Source of variation } & $\mathrm{N}$ & Pretest Mean & Posttest Mean & Lost Mean & Remark \\
\hline Meditation & 43 & 51.05 & 36.07 & 14.98 & Not Effective \\
Control & 21 & 48.10 & 42.10 & 6 & \\
\hline
\end{tabular}

Table 1 indicates that the students treated with meditation technique had pretest mean score of 51.05 and posttest mean score of 36.07 with lost mean 14.98 in their test anxiety, while the students in the control group who received conventional counselling had pretest mean score of 48.10 and posttest mean score of 42.10 with lost mean 6.0, therefore meditation technique is not effective in reducing the students' test anxiety since the posttest mean score of the client is above the norm 34.54.

\section{Research Question 2}

What are the differences in the Pretest and Posttest test anxiety mean scores of male and female students treated with meditation technique

Table 2: Pretest and Posttest test anxiety mean scores of male and female students treated with meditation technique.

\begin{tabular}{lccccc}
\hline Source of variation & $\mathrm{N}$ & Pretest Mean & Posttest Mean & Lost Mean & Remark \\
\hline Male & 25 & 51.05 & 36.07 & 14.98 & Reduced more \\
Female & 26 & 49.62 & 38.08 & 11.54 & \\
\hline
\end{tabular}

Table 2 indicates that the male students treated with meditation technique had pretest mean score of 51.05 and posttest mean score of 36.07 with lost mean 14.98 in their test anxiety, while the female students had pretest mean score of 49.62 and posttest mean score of 38.08 with lost mean 11.54 in their test anxiety. Therefore meditation technique reduced more of the male test anxiety.

\section{Testing the Null Hypotheses}

\section{Null Hypothesis 1}

There is no significant difference in the post-test test anxiety Mean scores of secondary school adolescents treated with meditation technique when compared with those in the control group. 
Table 3: ANCOVA on the posttest test anxiety mean scores of students treated with meditation technique and those who received conventional counselling.

\begin{tabular}{lcccccc}
\hline \multicolumn{1}{c}{ Source of variation } & SS & Df & MS & Cal.F & Crit.F & P $\geq 0.05$ \\
\hline Corrected Model & 406.149 & 2 & 203.074 & & & \\
Intercept & 640.122 & 1 & 640.122 & & & \\
Pretest & 35.124 & 1 & 35.124 & & & \\
Treatment Model & 405.806 & 1 & 405.806 & 14.06 & 4.00 & Significant \\
Error & 1645.785 & 57 & 28.873 & & & \\
Total & 87028.000 & 60 & & & & \\
Corrected total & 2051.933 & 59 & & & & \\
\hline
\end{tabular}

In table 3 it was observed that at 0.05 level of significance, the calculated $F=14.06$ is greater than the critical $F$ 4.00. therefore, the first null hypothesis is rejected. So, the difference in secondary school students' test anxiety reduction scores after meditation technique differs significantly with that of the conventional counselling group.

\section{Null Hypothesis 2}

There is no significant difference in the post-test test anxiety Mean scores of secondary school male and female adolescents treated with Meditation.

Table 4: ANCOVA on the posttest test anxiety mean scores of male students treated with meditation technique and female students treated mediation technique.

\begin{tabular}{lcccccc}
\hline \multicolumn{1}{c}{ Source of variation } & SS & Df & MS & Cal.F & Crit.F & P $\geq 0.05$ \\
\hline Corrected Model & 151.413 & 2 & 75.707 & & & \\
Intercept & 414.284 & 1 & 414.284 & & & \\
Pretest & 70.961 & 1 & 70.961 & & & \\
Treatment Model & 104.093 & 1 & 104.093 & 2.58 & 3.97 & NS \\
Error & 3112.587 & 77 & 40.423 & & & \\
Total & 112784.000 & 80 & & & \\
Corrected total & 3264.000 & 79 & & & & \\
\hline
\end{tabular}

Table 4 shows that at 0.05 level of significance, $1 \mathrm{df}$ numerator and $79 \mathrm{df}$ denominator, the calculated F 2.58 is less than the critical F 3.97. therefore, the null hypothesis is accepted. So, there is no significant difference in the reduction of male and female secondary school students' test anxiety treated with meditation technique

\section{Discussion}

\section{The effects of meditation technique on students' test anxiety}

Findings from the data analysed indicated that meditation technique is not effective on test anxiety among secondary school students. This finding disagreed with Putain and Best (2011). According to them, the results in the 
meditating group of the study revealed a significant improvement in depression, anxiety, internal tension and fatigue, but there was no significant effect of meditation on cognitive functions . The finding from the present study is in line with the finding of Ford (2008). Ford observed in his study that scores for the meditation group were found to increase at the post-test, but was not significantly higher than the control group.

Although this current study showed that there was a reduction on the level of test anxiety experienced by the participant adolescents, as indicated with the treatment group's mean loss over the control group, the finding is considered not effective on the adolescents test anxiety since the post-test mean score of the experimental group is above the test anxiety inventory norm. In contrast to this finding however, studies such as Akindele and Adeaga (2014) and Hoge, et al. (2013) showed that meditation technique is effective on cancer patients, anxiety disorders and in patients with memory loss. The finding of the study nonetheless supports research example,( Aftanas, \& Golocheikine, 2002)and centuries of anecdotal evidence that meditation helps relax people, release pent up stress, and make clients and patients alike feel more at peace. The contrast in the finding may be explained based on the idea that these studies adopted different aspects of meditations. Although many approaches to meditation include concentration and mindfulness techniques to some degrees adopted in this study, it is obvious that these approaches are not all the same. Accordingly, one might not expect identical results from practicing different kinds of meditation.

Moreover, finding from the study further revealed that the reduction of secondary school students' test anxiety after administering meditation treatment technique differs significantly with that of the conventional counselling administered on the control group.

\section{Implications of the Study}

These findings of this study on meditation in focusing attention and reducing distracting thoughts have clear implications.

From the present study it was found that mediation technique on adolescents in Anambra State was not effective, hence the implication of this to counsellors is that the technique should not be used alone in helping clients (especially adolescents in schools) overcome their test anxiousness in counselling. The counsellors thereby need to possess skills regarding various treatment therapies other than meditation to help the clients to relieve their anxiety during tests.

The present study has revealed that mediation technique was not effective on test anxiety as observed but the test anxiety can be reduced when treated. Therefore Guidance Counsellors and teachers in schools would henceforth see the need to explore through seminars and workshops, more 
effective counselling techniques to use in treatment of students with test anxiety; this will go a long way to enhance excellent academic performance among students who may have been previously hindered by test anxiety.

\section{Conclusion}

Based on the findings of this study, the following conclusions are made: although there was a reduction in the participants' level of test anxiety, meditation technique is not effective in treating test anxiety of the participants. Findings further revealed that the reduction of test anxiety of adolescents in schools after meditation treatment differs significantly with that of conventional counselling administered on the control group.

Finally, finding from the study revealed that meditation technique reduced the male and female secondary students test anxiety and it further revealed however that the reduction of male and female secondary school students test anxiety did not differ significantly.

\section{Recommendations}

Based on the finding of the study, the following recommendations are made:

1. Since the meditation technique, was found not to be effective, but reduced the anxiety level of students, guidance counsellors should seek for more effective counselling techniques in helping clients, especially students in overcoming their test anxiousness in counselling. If meditation should be used at all, it should be used alongside other techniques proven to have been effective on students' text anxiety.

2. Guidance Counsellors and teachers in schools should explore through seminars and workshops, more effective counselling techniques to use in treatment of students with test anxiety; this will go a long way to enhance excellent academic performance among students

\section{References:}

1. Anxiety Disorder Association of America (ADAA, 2012)"Test Anxiety". Retrieved 26 April, 2015, from www.apa.org.

2. Aftanas, LI., Golocheikine, SA. (September, 2002). "Non-linear dynamic complexity of the human EEG during meditation". Neuroscience Letters, 330 (2), 143-6.doi:10.1016/

3. Akindele, WO. \& Adeaga, TM. (2014).Contributions of test anxiety, study habits and locus of control to academic performance. British Journal of Psychology Research, 2(1), 14-24. Retrieved from www.ea-journals.org.

4. Bouras, N. \& Holt, G. (2007).Psychiatric and behavioural disorder in intelligence and developmental disabilities $\left(2^{\text {nd }} \mathrm{Ed}.\right)$. England: Cambridge University Press. 
5. Carter, EW., Wehby, J., Hughes, C., Johnson, SM., Plank, DR., Barton-Arwood, SM. (2005). Preparing adolescents with highincidence disabilities for high-stakes testing with strategy instruction.Preventing School Failure, 49, 55 - 62.

6. Cassady JC., (2010). Test anxiety: Contemporary theories and implications for learning. In J.C. Cassady (Ed.), Anxiety in schools: The causes, consequences and solutions for academic anxieties. Peter Lang, New York, NY.

7. Cassady, J. \& Johnson, R. (2002).Cognitive test anxiety and academic performance. Contemporary Educational Psychology, 27, 270-295.

8. Chapell, MS., Blanding, ZB., Silverstein, ME., Takahashi, M. Newman, B., Gubi, A., and Mccann, N. (2005). Test anxiety and academic performance in undergraduate and graduate students. Journal of Educational Psychology, 97(2), 268-274.

9. Deikman, AJ. (2003). Experimental Mediation. Journal of Nervous and Mental Disease, 136, 32 -73.

10. Egbochukwu, EO., Obodo, B., \& Obadan, NO. (2009). Efficacy of rational- emotive behaviour therapy on the reduction of test anxiety among adolescents in Secondary schools. European Journal of Social Sciences, 6,(4).

11. Ergene, T. (2003).Effective interventions on test anxiety reduction. HacettepeUniversity: Turkey. Retrieved from www.amtaa.org/res/ergene.pdf

12. Ford, J. (2008). Calming techniques. Retrieved on $15^{\text {th }}$ February, 2015, from www.meditate.com/

13. Hoge, EA., Bui, E., Marques, L., Metcalf, CA, Morris, LK, Robinaugh, DJ, Worthington, JJ., Pollack, MH., Simon, NM. (2013). Randomized controlled trial of mindfulness meditation for generalized anxiety disorder: effects on anxiety and stress reactivity.Journal of ClinicalPsychiat; 74(8), 786-92.doi: 10.4088/.

14. Hopko, DR., Crittendon, JA., Grant, E., \& Wilson, SA. (2005).The impact of anxiety on performance IQ.Anxiety, Stress, \& Coping, 18 (1), 17-35.

15. Kendra, C. (n.d) Causes of Test Anxiety .The New York Times Company.Retrieved 26 January 2015.

16. Kendra, C (N.d). "Test Anxiety Symptoms".About.com. Retrieved January 2015.

17. Mychailyszyn, MP., Mendez, JL., \& Kendall, PC. (2010). School functioning in youth with and without anxiety disorders: Comparisons by diagnosis and comorbidity. School Psychology Review, 39 (1), 106121. 
18. Nwogu BC. (2006). Educational Research: Basic Issues and Methodology. Enugu: University Publishers.

19. Onyekuru, BU. \& Ibegbunam, JO. (2014).Relationships among test anxiety, locus of control and academic achievement among college students.European Scientific Journal, 10, (13).

20. Ozsivadjian, A., Knott, F., \& Magiati, I. (2012). Parent and child perspectives on the nature of anxiety in children and young people with autism spectrum disorders: A focus group study. Autism: The International Journal of Research \& Practice, 16 (2), 107-121

21. Putwain DW., Best, N. (2011). Fear appeals in the primary classroom: effects on test anxiety and test grade. Learning and Individual Differences, 21 580-584

22. Putwain, DW., Woods, KA., Symes, W. (2010). Personal and situational predictors of test anxiety of students in post-compulsory education.British Journal of Educational Psychology, 80, 137-160

23. Vaez, M.; Laflamme, L. (2008)."Experienced stress, psychological symptoms, self-rated health and academic achievement: A longitudinal study of Swedish university students .Social Behaviour and Personality36, 183-196. doi:10.2224/sbp.2008.36.2.183.

24. Salend, SJ. (2012). Teaching students not to sweat the test .Phi Delta Kappan93 (6): 20-25. doi:10.1177/003172171209300605.

25. Spielberger, C. (2005). The nature, assessment, and reduction of test anxiety. In, Academic benefits from test-anxiety reduction programs. Symposium at the American Psychological Association Convention, Washington, D.C.

26. Vaez, M.; Laflamme, L. (2008).Experienced stress, psychological symptoms, self-rated health and academic achievement: A longitudinal study of Swedish university students .Social Behaviour and Personality 36: 183-196. Doi:10.2224/sbp.2008.36.2.183

27. Zondi, L. (2013). The effect of breathing techniques on test anxiety among students at the university of Zululand. Retrieved on $22^{\text {nd }}$ January, 2015 from uzspace.uzulu.ac.za/ 